\title{
GRADO DE APOYO FAMILIAR Y SU RELACIÓN CON EL GRADO DE ADHESIÓN A LA NORMA CRISTIANA DE NO BAILAR EN LOS ADOLES- CENTES DE LA ASOCIACIÓN ARGEN- TINA DEL NORTE, AÑO 2008
}

\author{
Caviglione Botto, Dario M. \\ Asociación Argentina del Norte de la \\ Iglesia Adventista del Séptimo Día \\ dariocaviglione@gmail.com
}

Fecha de recepción: Agosto 2012 Fecha de aceptación y versión final: Septiembre 2012

\section{Resumen}

La presente investigación busca establecer la relación entre el grado de apoyo familiar recibido y el grado de adhesión a la norma de conducta cristiana de no bailar sustentada por la Iglesia Adventista del Séptimo Dia, en los adolescentes de 13 a 18 años de edad, miembros de la misma, en las noventa iglesias organizadas de la Asociación Argentina del Norte, en el año 2008. Esta investigación es de tipo empirica, cuantitativa, descriptiva-correlacional, no experimental, de corte transversal, y muestra que hay relación altamente significativa, aunque baja, entre el grado de apoyo familiar y el grado de adhesión a la norma de conducta cristiana de no bailar. Que, la religiosidad de los padres y el culto familiar se relacionan de manera altamente significativa, aunque baja, con el grado de adhesión a la norma cristiana de no bailar y que ni el ambiente familiar, el soporte parental o el control parental, se relacionan con el grado de adhesión a la norma cristiana de no bailar.

Palabras clave: Norma cristiana, adhesión a la norma, baile
en adolescentes. 


\section{Introducción}

La iglesia está viviendo un fenómeno secularizador, ${ }^{1}$ algunas de las características involucradas en este fenómeno son las siguientes: 1) Declinación de la religión como factor modelador de la vida; 2) la pérdida de la fe; 3) el desarrollo de una forma peculiar de pensamiento, caracterizada por el racionalismo, el relativismo, el pragmatismo, el positivismo, el empirismo y el existencialismo; 4) la conformidad con el mundo, manifestada en la adaptación a los valores socio - culturales contemporáneos; la influencia del secularismo; y a ello se suma el surgimiento del postmodernismo, a fines de la década de 1960 y principios de 1970. ${ }^{2}$

La República Argentina, como muchos otros países, en las últimas décadas vivió cambios sociales. Los mismos también afectan a los adolescentes de la iglesia, que hacen frente a la influencia de corrientes como el postmodernismo, con su bús-

1 Daniel Scarone, "Un caballo de Troya en la iglesia de Dios", Ministerio adventista, noviembre-diciembre, 1987, 16.

2 Gary Land, "El desafío del postmodernismo: ¿Cómo debe responder el cristiano?", Diálogo universitario $8, \mathrm{n}^{\circ} 1$ (1996): 6. queda de una sociedad sin fundamentos o valores ${ }^{3}$ y del secularismo en sus distintos matices.

La presente investigación está relacionada con una de las principales vías de apoyo que reciben los adolescentes y una de las normas cristianas menos aceptadas, según Valuegenesis.

\section{Formulación del problema general}

Por lo descrito, se plantea la siguiente interrogante: ¿Cuál es la relación entre el grado de apoyo familiar recibido y el grado de adhesión a la norma de conducta cristiana de no bailar sustentada por la Iglesia Adventista del Séptimo Día (IASD), en adolescentes de 13 a 18 años de edad de las noventa iglesias organizadas de la Asociación Argentina del Norte (AAN), año 2008?

\section{Objetivo general}

El objetivo general de la presente investigación es el siguiente: Establecer la relación entre el grado de apoyo familiar recibido y el grado de adhesión a la norma de conducta cristiana de no bailar sustentada por la IASD, en

3 Ibíd., 8. 
los adolescentes de 13 a 18 años de edad que son miembros de la misma, en las noventa iglesias organizadas de la AAN, año 2008.

\section{Hipótesis general}

Hipótesis alterna (H1): Existe relación entre el grado de apoyo familiar recibido y el grado de adhesión a la norma de conducta cristiana de no bailar sustentada por la IASD, en los adolescentes de 13 a 18 años de edad, miembros de las noventa iglesias organizadas de la AAN, año 2008.

Hipótesis nula (Ho): No existe relación entre el grado de apoyo familiar recibido y el grado de adhesión a la norma de conducta cristiana de no bailar sustentada por la IASD, en los adolescentes de 13 a 18 años de edad, miembros de las noventa iglesias organizadas de la AAN, año 2008.

\section{Antecedentes de la investigación}

En 1990, la División Norteamericana (DNA) llevó adelante un estudio llamado Valuegenesis, con cerca de 15.000 jóvenes estudiantes de $6^{\circ}$ a $12^{\circ}$ grados. ${ }^{4}$

4 Roger L. Dudley, Valuegenesis: Faith in the Balance, ed. V. Bailey Gillespie (Riverside, CA: La Sierra Univer-
El mismo analizó la contribución en el desarrollo de la madurez de la fe de los jóvenes, de las tres principales vías de apoyo espiritual que reciben: el hogar, la escuela y la iglesia. ${ }^{5}$

Una de las conclusiones de esta investigación es que la familia parece ser la vía más positiva para el cumplimiento de las normas, especialmente aquellas relacionadas a la cultura popular y entre ellas, la de no bailar. ${ }^{6} \mathrm{Va}$ luegenesis 2, realizado por la DNA diez años después con un grupo de 21.000 adolescentes, confirma lo mismo. ${ }^{7}$ Este último estudio, con características similares al primero, afirma que la falta de religiosidad de los miembros de la familia y la falta de refuerzo de las normas en el hogar se relaciona directamente con la baja adhesión a las normas por parte de los adolescentes. ${ }^{8}$

sity, 1992):13-15.

5 Gail Rice y V. Bailey Gillespie, "Valuegenesis: A Mega study of Faith Maturity and its Relationship to Variables within the Home, School, and Church", Journal of Research on Christian Education 1, no 1 (1992): 50 .

6 Ibíd., 65-66.

7 Caron Oswald, "Valuegenesis 2: Good News Part II", The Pacific Union Recorder, Julio, 2005, 22-23.

8 Gillespie, V. Bailey y Michael J. Donahue, Valuegenesis - Ten Years Later: A Study of Two Generations, (River- 
A su vez, Gillespie y Donahue identificaron 19 influencias positivas de la vida familiar, relacionadas al desarrollo de una fe madura, a la fidelidad a la iglesia y al compromiso religioso. Luego, las mismas fueron agrupadas en cuatro categorías, una de las cuales es el clima familiar. ${ }^{9}$

En la década de 1990 se realizó otro estudio Valuegénesis en la División del Pacífico Sur (DPS). Esta investigación, al igual que las dos mencionadas anteriormente, muestra que las tres áreas: familia, iglesia y escuela, están conectadas en el apoyo a los adolescentes y jóvenes para el desarrollo de una fe madura. ${ }^{10}$ A su vez, afirma que hay una fuerte relación positiva entre el culto familiar y el compromiso cristiano en los jóvenes. ${ }^{11}$

Otro estudio hecho con jóvenes adventistas hispanos de la DNA, llamado AVANCE, observó a 1163 jóvenes y 2143 adultos. El mismo, menciona que el 75,4\% de los jóvenes que reportaron ser fieles a la iglesia, side, CA: Hancock Center Publications, 2004), 249.

9 Gillespie y Donahue, 320 .

10 Bruce Manners, "Youth Survey Results Released", Record 98, no 21 (5 de junio, 1993), 8.

11 Ibíd. también manifestaron tener lazos familiares afectivos. ${ }^{12}$

Dudley, en un estudio hecho con familias adventistas, afirma que los adolescentes que provienen de hogares donde ambos padres asisten a la iglesia y participan del culto familiar, son más propensos a permanecer en la iglesia cuando llegan a ser adultos. ${ }^{13}$

En otro estudio, Dudley analiza la permanencia en la iglesia de un grupo de 1500 adolescentes de Canadá y Estados Unidos, durante una década. Encontró que una de las ocho variables asociadas a la permanencia en la iglesia en los últimos diez años es la participación frecuente en el culto familiar. ${ }^{14}$

En otra investigación realizada en Estados Unidos con 801 adolescentes adventistas del séptimo día se encontró que la principal razón, para no usar drogas, fue el compromiso con Cristo,

12 Johnny Ramírez-Johnson y Edwin I. Hernández, AVANCE: A Vision for a New Mañana (Loma Linda, CA: Loma Linda Press, 2003).

13 Roger L. Dudley, "Why Our Teenagers Leave the Church", Spectrum 28, no 4 (2000): 27.

14 Roger L. Dudley, "Youth Religious Commitment over Time: a Longitudinal Study of Retention", Review of Religious Research 41, no 1 (1999): 115-116. 
la segunda razón fue no querer chasquear a los padres y la tercera razón fue no querer romper las reglas. ${ }^{15}$

\section{La adolescencia}

La palabra adolescencia deriva del latín adolescere, que significa crecer. ${ }^{16}$ Es un período que implica el desarrollo físico y a la vez, el aprendizaje como preparación para la independencia y la vida adulta. ${ }^{17}$ Es un período de tránsito ${ }^{18} \mathrm{y}$ consolidación de tendencias de comportamiento. ${ }^{19}$

\section{González Núñez propone}

15 Roger L. Dudley, Patricia B. Mutch y Robert J. Cruise, "Religious Factors and Drug Usage among SeventhDay Adventist Youth in North America", Journal for the Scientific Study of Religion 26, no 2 (1987): 218-224.

16 Rolf E. Muuss, Teorías de la adolescencia (México: Paidós, 1993), 10.

17 María Lameiras Fernández et al., "Determinantes del inicio de las relaciones sexuales en adolescentes españoles", Cuadernos de medicina psicosomática y psiquiatría de enlace, no 71-72 (2004): 68.

18 Manuel Martín Serrano, "Adolescencia producida y adolescencia vivida: las contradicciones de la socialización", en Congreso ser adolescente hoy: Libro de ponencias, ed. Fundación de Ayuda contra la Drogadicción (Madrid: Ancares Gestión Gráfica, 2005), 73, 81.

19 María José Rodrigo et al., "Relaciones padres-hijos y estilos de vida en la adolescencia”, Psicothema 16, nº 2 (2004): 203. considerar varias adolescencias. ${ }^{20}$ Urbaitel, en cambio, divide la adolescencia en solo dos etapas: los púberes-adolescentes y los jóvenes-adolescentes. Los primeros, según él, tienen de 13 a 15 años y los últimos, de 15 a 18 años. ${ }^{21}$

Por otro lado, algunos dividen la adolescencia en tres etapas: la etapa inicial, que va desde los 11 a los 13 años; la etapa media, que abarca de los 13 a los 15 años y la tardía, que comprende de los 15 a los 18 años. 22

\section{Características de la identi- dad adolescente}

Blos considera la adolescencia como un segundo proceso

20 José de Jesús González Núñez, "Adolescencia", en Herramientas para la actividad tutorial, ed. Alejandra Villanueva (México: Universidad de Guadalajara, 2004), 21.

21 Pablo Urbaitel, "Adolescencia, tribus urbanas y cultura joven: algunas reflexiones acerca de las características de los alumnos de nivel medio", Anuario del departamento de ciencias de la comunicación vol. 4 (1999), bajo "adolescencia tribus urbanas", http://rephip.unr. ed.ar/bitstream/handle/2133/782/Adolescencia, $\% 20$ tribus $\% 20$ urbanas $\% 20$ y\%20cultura \%joven.pdf? sequence $=1$ (consultado: 16 de enero, 2009).

22 María G. Yanes García y María del C. Morales Okata, "Algunas características de la adolescencia", Medisur 2, $\mathrm{n}^{\circ}$ 1 (2004): 65, 66. 
de individuación. El primero se completa en el tercer año de vida y el segundo con la adolescencia. ${ }^{23}$ Una de las principales tareas durante la adolescencia es la construcción de la identidad, ${ }^{24}$ para lograrlo, el adolescente echa mano de los materiales y prácticas que tiene al alcance. ${ }^{25}$ En este sentido, el adolescente es materia moldeable y receptiva, abierta a las influencias de los modelos de la sociedad. ${ }^{26}$

Algunas de las características del adolescente en el mundo posmoderno son: 1) Vivir el presente. ${ }^{27}$ 2) El culto al cuerpo,

23 Peter Blos, La transición adolescente (Buenos Aires: ASAPPIA, 1991), 99, 119.

24 Jaume Funes Artiaga, "Propuestas para observar y comprender el mundo de los adolescentes: o cómo mirarlos sin convertirlos en un problema", en Congreso ser adolescente hoy: Libro de ponencias, ed. Fundación de Ayuda contra la Drogadicción (Madrid: Ancares Gestión Gráfica, 2005), 43.

25 Ibíd.

26 María José Rodrigo et al., "Relaciones padres-hijos y estilos de vida en la adolescencia", Psicothema 16, no 2 (2004): 203.

27 María José Díaz-Aguado Jalón, "La violencia de los adolescentes como reflejo de la sociedad adulta", en Congreso ser adolescente hoy: Libro de ponencias, ed. Fundación de Ayuda contra la Drogadicción (Madrid: Ancares Gestión Gráfica, 2005), 67. expresado en su vestir, ${ }^{28}$ y una serie de elementos que hacen a la estética corporal: maquillajes, tatuajes, piercing, joyas, ropas, entre otros. ${ }^{29}$ Es importante señalar que en los lugares de baile, el ambiente está preparado para exhibir el cuerpo. ${ }^{30}$ 3) La imitación es ser y hacer lo que el grupo es y hace, ${ }^{31}$ de esta manera, el joven adolescente construye su identidad personal a partir de conocer y reconocerse en otros. ${ }^{32}$ 4) El tribalismo, pues, en ella encuentra para su vida un sentido

28 Pablo Urbaitel, "Adolescencia, tribus urbanas y cultura joven: algunas reflexiones acerca de las características de los alumnos de nivel medio", Anuario del departamento de ciencias de la comunicación vol. 4 (1999), 239.

29 Argiro Velázquez Pérez, "Lenguaje e identidad en los adolescentes de hoy", La ágora usb 7, $\mathrm{n}^{\circ} 1$ (enero-julio 2007): 85-107.

30 Leo Hendry, "Hedonistic and 'Cool', but Not-So-Clever?: Being Adolescent in the U. K.", en Congreso ser adolescente hoy: Libro de ponencias, ed. Fundación de Ayuda contra la Drogadicción (Madrid: Ancares Gestión Gráfica, 2005), 137.

31 Elena Rodríguez, "A vueltas con la cultura juvenil", en Los hijos 'raros': claves para que los padres entiendan, ed. Fundación de Ayuda contra la Drogadicción (Madrid, Ancares Gestión Gráfica, 2004), 47, 49.

32 Juan C. Silva, "Juventud y tribus urbanas: en busca de la identidad", Ultima década, $\mathrm{n}^{\circ} 17$ (septiembre 2002): 123. 
de pertenencia. ${ }^{33}$ 5) El consumismo, pues a partir de la década de 1980, se universalizaron gustos, normas y costumbres. ${ }^{34}$ 6) Identidad y valores materialistas y egocentristas. ${ }^{35}$

Se debe señalar que es en la adolescencia donde el joven alcanza "una comprensión personal más profunda del significado y contenido de la religión y la ve más claramente como cosa propia" ${ }^{36} \mathrm{Al}$ comienzo de este período, comienza a pensar en términos abstractos y a moverse de la esfera de lo concreto. ${ }^{37} \mathrm{De}$ -

33 Carles Feixa Pámpols, “¿Tribus? ¿Urbanas?”, en Congreso ser adolescente hoy: Libro de ponencias, ed. Fundación de Ayuda contra la Drogadicción (Madrid: Ancares Gestión Gráfica, 2005), 249.

34 Ángela Marulanda, "Los padres frente al proceso de formación de sus hijos", en II Congreso La familia en la sociedad del siglo XXI: Libro de ponencias, ed. Fundación de Ayuda contra la Drogadicción (Madrid, Ancares Gestión Gráfica, 2004), 76.

35 Elena G. de White, La conducción del niño (Florida, Bs. As.: Asociación Casa Editora Sudamericana, 1964), 165.

36 Fowler D. Brooks, Psicología de la adolescencia (Buenos Aires: Editorial Kapelusz, 1957), 340

37 Víctor Andrés Korniejczuk, “Development of the concept of salvation in Argentinean and Paraguayan Seventhday Adventist Children and Adolescents from Ages 6 to 17 Years" (Tesis Doctoral, sarrolla la habilidad de razonar lógicamente y de cuestionar todo. 38

\section{Adolescencia y actitud hacia las normas}

Al llegar a la adolescencia, el joven lucha por su independencia y comienza a distanciarse de sus padres, ${ }^{39}$ se manifiesta una actitud de rebeldía que muchas veces es difícil de encauzar, ${ }^{40}$ por consiguiente, es necesario mantener la disciplina dentro del hogar. Para ello, las normas deben estar claramente definidas, como así también las consecuencias en caso de que no sean respetadas.

La impunidad frente a las transgresiones, reduce la eficacia de las reglas. ${ }^{41}$ Además, saber

Andrews University, 1994), 24.

38 Donna Habenicht, Enséñales a amar: ideas prácticas acerca de cómo ayudar a tu niño a crecer espiritualmente (Bogotá: APIA, 2000), 134.

39 Alejandra Vallejo-Nágera, La edad del pavo: consejos para lidiar con la rebeldía de los adolescentes (Madrid: Ediciones Temas de Hoy, 1997), 42.

40 Juana Palma Vaillant. "Bases éticas para el ejercicio de la autoridad familiar", Santiago, no 106 (2005): 54.

41 María José Díaz-Aguado Jalón, "La violencia de los adolescentes como reflejo de la sociedad adulta", en Congreso ser adolescente hoy: Libro de ponencias, ed. Fundación de Ayuda contra la 
escuchar es otra herramienta positiva a la hora de resolver los conflictos con los hijos. ${ }^{42}$

\section{El apoyo familiar}

La familia es esencial en el proceso de socialización, ya que es "la célula social básica". 43 En ella se aprenden e imitan los primeros patrones de conducta. A continuación se desarrollan cinco elementos de apoyo relacionados a la vida familiar adventista, que son los más destacados en la literatura revisada: la religiosidad de los padres, el ambiente familiar, el soporte parental, el control parental y el culto familiar.

\section{Religiosidad de los padres}

El rol que ocupa la religión en la propia vida, ${ }^{44}$ tiene que ver con lo que se debe ser, en contraste con la espiritualidad, "que implica simplemente ser". ${ }^{45}$ En

Drogadicción (Madrid: Ancares Gestión Gráfica, 2005), 62.

42 Vallejo-Nágera, 62.

43 Juana Palma Vaillant. "Bases éticas para el ejercicio de la autoridad familiar", Santiago, $\mathrm{n}^{\circ} 106$ (2005): 53.

44 Craig R. Crowden y Scott D. Bradshaw, "Religiosity and Sexual Concerns", International Journal of Sexual Health 19, no 1 (2007): 16.

45 Armando Rivera-Ledesma y Ma- otras palabras, alguien puede ser religioso pero no necesariamente espiritual.

La religiosidad ha sido clasificada conforme a su orientación. Gordon Allport hace una distinción entre religiosidad intrínseca y extrínseca. Según él, la persona de religiosidad intrínseca vive su religión como lo más importante en su vida. En cambio, la persona de religiosidad extrínseca usa la religión en un sentido utilitario. ${ }^{46}$

A su vez, Batson, Schoenrade y Ventis, hacen referencia a un tercer tipo de orientación la religiosidad Quest: ${ }^{47}$ ésta es

ría Montero, "Espiritualidad y religiosidad en adultos mayores mexicanos", Salud mental 28, no 6 (diciembre 2005): 57.

46 Gordon W. Allport y J. M. Ross, "Personal Religious Orientation and Prejudice", Journal of Personality and Social Psychology $5, \mathrm{n}^{\circ} 4$ (1967): 432-443.

47 Se han realizado varios estudios explorando las orientaciones de la religiosidad. Véase: Gillespie y Donahue, 81; Avidan Milevsky y Mary J. Levitt, "Intrinsic and Extrinsic Religiosity in Preadolescence and Adolescence: Effect on Psychological Adjustment", Mental Health, Religion \& Culture 7, $\mathrm{n}^{\circ} 4$ (2004): 307-321; Barry Gane y Jimmy Kijai, "The Relationship Between Faith Maturity, Intrinsic and Extrinsic Orientations to Religion and Youth Ministry Involvement", The Journal of Youth Ministry 
definida como una apertura y aproximación hacia preguntas existenciales. $^{48}$

La religiosidad ha sido objeto de observación en diferentes investigaciones. En una investigación realizada con familias adventistas a lo largo de diez años, Dudley relaciona la asistencia frecuente de los padres a la iglesia con la disposición a permanecer en la misma por parte de los hijos adolescentes. ${ }^{49}$ Otro estudio indica que los adolescentes que provienen de hogares donde ambos padres son adventistas, tienden a ser más felices con su religión..$^{50}$ De acuerdo a otra investigación cuando los padres dialogan de asuntos de fe con sus hijos, éstos también demuestran una conducta más religiosa. ${ }^{51}$

4, no 2 (Spring 2006): 49-64; Cowden y Bradshaw, 15-23.

48 C. Daniel Batson, Patricia Schoenrade y W. Larry Ventis, Religion and the Individual: A Social-Psiychological Perspective (New York: Oxford university Press, 1993), 188.

49 Roger L. Dudley, "Why Our Teenagers Leave the Church", Spectrum 28, $\mathrm{n}^{\circ} 4$ (2000): 27.

50 Janet Leigh Kangas, "A Study of the Religious Attitudes and Behaviors of Seventh-Day Adventist Adolescent in North America Related to their Family, Educational and Church Backgrounds" (Tesis Doctoral, Andrews University, 1988), 135.

51 Douglas L. Flor y Nancy Flana-

\section{Ambiente familiar}

La familia es un refugio; un espacio de intimidad, donde cada uno se manifiesta como realmente es. Ella regula y canaliza los afectos y los sentimientos de cada uno de sus miembros. ${ }^{52}$ La familia ejerce una influencia que acompaña a los hijos a lo largo de toda la vida. ${ }^{53}$ Por ello, un clima relacional que se caracterice por el afecto, el apoyo y la comunicación, favorecen el desarrollo positivo del adolescente. ${ }^{54}$

A pesar de que el relacionamiento familiar cambia durante

gan Knapp, "Transmission and Transaction: Predicting Adolescent's Internalization of Parental Religious Values", Journal of Family Psychology 15, $\mathrm{n}^{\circ} 4$ (2001): 634 .

52 Ricardo Montoro Romero, "La familia en su evolución hacia el siglo XXI", en II Congreso La familia en la sociedad del siglo XXI: Libro de ponencias, ed. Fundación de Ayuda contra la Drogadicción (Madrid, Ancares Gestión Gráfica, 2004), 12, 13.

53 Ana Miranda Casas y Josefa Pérez Blasco, "Socialización familiar, pese a todo", en Congreso ser adolescente hoy: Libro de ponencias, ed. Fundación de Ayuda contra la Drogadicción (Madrid, Ancares Gestión Gráfica, 2005), 339.

54 Alfredo Oliva, Águeda Parra y Enrique Arranz, "Estilos relacionales parentales y ajuste adolescente", Infancia y aprendizaje 31, $\mathrm{n}^{\circ} 1$ (2008): 105. 
la pubertad, 55 en esta etapa, el joven continúa necesitando que sus padres se muestren cercanos y le ofrezcan sustento emocional. ${ }^{56}$

Así también, un buen ambiente familiar favorece la transmisión de valores y normas sociales a los hijos, ${ }^{57}$ la asistencia a los cultos religiosos ${ }^{58}$ y el desarrollo de un mayor nivel de autoestima. ${ }^{59}$

En otros estudios, igualmente está asociado a un inicio más tardío de la actividad sexual, ${ }^{60}$ a

55 Laurence D. Steinberg, Adolescence (China: Mc Graw Hill, 2005), 136.

56 Ana Miranda Casas y Josefa Pérez Blasco, "Socialización familiar, pese a todo", en Congreso ser adolescente hoy: Libro de ponencias, ed. Fundación de Ayuda contra la Drogadicción (Madrid, Ancares Gestión Gráfica, 2005), 343.

57 Angel Rodriguez y Ginesa Torrente, "Interacción familiar y conducta antisocial", Boletín de psicología 78 (Julio 2003), 8.

58 Roger L. Dudley y Randall L. Wisbey, "The Relationship of Parenting Styles to Commitment to the Church among Young Adults", Religious Education 95, $\mathrm{n}^{\circ} 1$ (Winter 2000), 38.

59 María Cruz C. García Linares, Santiago Pelegrina y Juan Lendinez, "Los estilos educativos de los padres y la competencia psicosocial de los adolescentes", Anuario de Psicología 33, nº 1 (2002), 90.

60 María Lameiras Fernández et al., "Determinantes del inicio de las relacio- una menor implicación en conductas problemáticas ${ }^{61}$ y a un menor riesgo de consumo de tabaco, bebidas alcohólicas y drogas. $^{62}$

\section{Soporte parental}

Durante la adolescencia, los jóvenes necesitan padres cercanos que les brinden soporte mediante una comunicación fluida. Esto es tan importante como lo era durante la infancia. Les ayudará a hacer frente a los cambios y a los momentos difíciles. ${ }^{63}$

\section{En general, la comunicación}

nes sexuales en adolescentes españoles", Cuadernos de medicina psicosomática y psiquiatría de enlace, no 71-72 (2004): 71.

61 Águeda Parra y Alfredo Oliva, "Un análisis longitudinal sobre las dimensiones relevantes del estilo parental durante la adolescencia", Infancia y aprendizaje 29, no 4 (2006), 466, 467.

62 Véase Emmanuel N. Kuntsche y Hervé Kuendig, "What is Worse? A Hierarchy of Family-Related Risk Factors Predicting Alcohol Use in Adolescence", Substance Use \& Misuse 41 (2006), 82; Marina J. Muñoz-Rivas y José Luis Graña López, "Factores familiares de riesgo y de protección para el consumo de drogas en adolescentes", Psicothema $13, \mathrm{n}^{\circ} 1$ (2001), 93.

63 Alfredo Oliva Delgado y Águeda Parra Jiménez, "Contexto familiar y desarrollo psicológico durante la adolescencia", en Familia y desarrollo psicológico, ed. E. Arranz (Madrid: Pearson Educación, 2004), 114. 
suele verse afectada al inicio de la pubertad, ya que los chicos y chicas hablan menos de manera espontánea. ${ }^{64}$ Además, han surgido nuevos agentes de socialización que compiten con los tradicionales, ${ }^{65}$ por lo que el estilo de conversación de los adolescentes se asemeja a la manera en que se comunican a través del chat o de los SMS de los celulares; no hay formalidad, reflexión ni revisión. ${ }^{66}$

Según un estudio, los hijos que mantienen una comunicación fluida con sus padres, señalan que los lugares donde se dicen las cosas importantes son la familia y la escuela; en tanto que aquellos que tienen una mala relación con sus padres creen que las cosas importantes las dicen los amigos y los medios de comunicación. ${ }^{67}$

64 Alfredo Oliva, "Relaciones familiares y desarrollo adolescente", Anuario de psicología 37, n 3 (2006), 213.

65 Javier Elzo Imaz, "El grito de los adolescentes", en Congreso ser adolescente hoy: Libro de ponencias, ed. Fundación de Ayuda contra la Drogadicción (Madrid: Ancares Gestión Gráfica, 2005), 85.

66 José Antonio Gabelas Barroso, "Crecer entre pantallas", en Congreso ser adolescente hoy: Libro de ponencias, ed. Fundación de Ayuda contra la Drogadicción (Madrid: Ancares Gestión Gráfica, 2005), 277.

67 Ignacio Megías Quirós, Comu-
Otros estudios relacionan de manera positiva el soporte parental con el autoconcepto, ${ }^{68} \mathrm{el}$ rendimiento escolar, ${ }^{69}$ el relacionamiento afectivo con los iguales ${ }^{70}$ y el bienestar mental de los hijos adolescentes. ${ }^{71}$ También es asociado de manera negativa con el consumo de drogas, marihuana, cigarrillo y alcohol, ${ }^{72}$ la

nicación y conflictos entre padres e hijos, ed. Fundación de Ayuda contra la Drogadicción (Madrid: Ancares Gestión Gráfica, 2003), 32.

68 Estefanía Estévez López et al., "Estilos de comunicación familiar, actitud hacia la autoridad institucional y conducta violenta del adolescente en la escuela", Psicothema 19, no 1 (2008), 112.

69 Véase Elisabeth C. Cooksey y Michelle M. Fondell, "Spending Time with His Kids: Effects of Family Structure on Father's and Children's Live", Journal of Marriage and Family 58, n 3 (August 1996), 693; Megías Quirós, 54.

70 Inmaculada Sánchez-Queija y Alfredo Oliva, "Vínculos de apego con los padres y relaciones con los iguales durante la adolescencia", Revista de psicología social 18, no 1 (2003), 79, 82, 84.

71 Elizabeth C. Hair et al., "The Continued Importance of Quality Parent-Adolescent Relationships during Late Adolescence", Journal of Research on Adolescence 18, $\mathrm{n}^{\circ} 1$ (March 2008), 195.

72 Megan L. Mayberry, Dorothy L. Espelage y Brian Koenig, "Multilevel Modeling of direct Effects and Interactions of Peers, Parents, School, and Community Influences on Adolescent Substance Use", Journal of Youth and Adolescence 38, n 8 (2009): 1045, 1047. 
conducta violenta ${ }^{73}$ y delincuen$\mathrm{te}^{74}$ y sentimientos de soledad y de victimización escolar. ${ }^{75}$

\section{Control parental}

Durante la adolescencia hay cambios en las funciones de la familia. ${ }^{76}$ En la infancia los hijos necesitan nutrición, protección y socialización. En la adolescencia, aun cuando estos elementos continúan siendo importantes, requieren más soporte, guía y dirección. ${ }^{77}$ Por un lado, los adolescentes continúan necesitando del afecto de los padres ${ }^{78}$ y por

73 Estefanía Estévez López, Belén Martínez Ferrer y Gonzalo Musitu Ochoa, "Padres y profesores: un análisis de su influencia en la configuración de la actitud hacia la autoridad institucional en adolescentes y su comportamiento en la escuela", en Congreso ser adolescente hoy: Libro de ponencias, ed. Fundación de Ayuda contra la Drogadicción (Madrid: Ancares Gestión Gráfica, 2005), 439, 440 .

74 Hair et al., 194.

75 David Moreno Ruiz, Sergio Murgui Pérez y Gonzalo Musitu Ochoa, "Problemas de comunicación familiar, victimización escolar y soledad en los adolescentes", en Congreso ser adolescente hoy: Libro de ponencias, ed. Fundación de Ayuda contra la Drogadicción (Madrid: Ancares Gestión Gráfica, 2005), 393, 394.

76 Steinberg, 136.

77 Ibíd. 19. otro, se hace necesario el establecimiento de límites y el monitoreo de lo que realizan. ${ }^{79}$ Así, el ejercicio de la autoridad versus la permisividad se constituyen en uno de los ejes del control parental, que resultarán en la efectividad de la transmisión de valores y normas. ${ }^{80}$

El control parental, aunque debiera disminuir a medida que los hijos crecen, ${ }^{81}$ se torna en algo necesario, especialmente en la adolescencia temprana. ${ }^{82} \mathrm{El}$ control parental que incluye monitoreo y soporte, a través del diálogo y el afecto, es un aliado para el desarrollo físico, emocional, social y moral del adolescente. ${ }^{83}$

\section{Culto familiar}

La adoración a Dios en familia comenzó en el Jardín del Edén. El Creador visitaba a Adán y Eva ${ }^{84}$ y ellos se deleita-

79 Oliva, 220.

80 Megías Quirós, 13.

81 Parra y Oliva, 466.

82 Oliva, 221.

83 Palma Vaillant, 54; Diana Baumrind, "Effects of Authoritative Parental Control on Child Behavior", 887, 905; Torío López, Peña Calvo e Inda Caro, 63; Oliva Delgado y Parra Jiménez, 109; Oliva, Parra y Arranz, 101, 104.

84 Elena G. de White, Alza tus ojos (Florida, Bs As.: Asociación Casa Edito- 
ban en estar en comunión directa con El. ${ }^{85}$ Luego de la caída, Adán y su familia continuaron adorando a Dios, y él era el responsable de presentar las ofrendas por medio de sacrificios de animales. ${ }^{86}$ Abel, uno de sus hijos, aprendió a hacer lo mismo (Gn 4:3-5). De esta manera, "el jefe de cada familia era dirigente y sacerdote de su propio conjunto familiar". 87

La adoración a Dios erigiendo altares es mencionada en la Biblia numerosas veces. Noé salió del arca junto con su familia, luego del diluvio y levantó un altar (Gn 8:18-20). Abraham erigió varios altares para adorar a Dios (Gn 12:7, 8; 13:4, 18; 22:9). Isaac (Gn 26:25) y Jacob (Gn 33:20; 35:7) hicieron lo mismo. Otros construyeron un altar como un monumento recordativo de su adoración a Dios, para ellos y sus descendientes (Jos 22:10, 26-28).

En el mandato divino dado a Israel (Dt 6:4-9) queda claro que "el hogar es siempre el espacio donde la Palabra de Dios es ob-

ra Sudamericana, 1982): 196.

85 Elena G. White, Patriarcas y profetas (Florida, Bs. As: Asociación Casa Editora Sudamericana, 2001), 32.

86 Ibíd., 51.

87 Ibíd., 52. jeto de enseñanza y práctica". 88 La vida religiosa en el hogar, cuando la Palabra es enseñada y practicada, se transforma en un acto misionero. De esta manera, como dice Padilla, "la misión que encuentra su punto de inicio en el hogar, también coloca en su centro la Palabra de Dios". 89

En Abraham se aprecia el ejemplo de un hombre que hacía de su hogar un centro de adoración a Dios (Gn 18:19). También, su casa se transformaba en un espacio para la misión. Cuando Abraham envió a Eliezer, ${ }^{90}$ (Gn 24)

En otra referencia, Elena de White declara de Abraham: "dondequiera que plantaba su tienda, cerca levantaba su altar, llamando para el sacrificio de la mañana y la tarde a cada miembro de su familia". ${ }^{91}$

En el Nuevo Testamento los requisitos para los ancianos y los

88 88. C. René Padilla, Bases bíblicas de la misión: perspectivas latinoamericanas (Buenos Aires: Nueva Creación, 1998).

89 Ibíd, 75.

90 White, Patriarcas y profetas, 170.

91 Elena G. de White, "Family Prayer", The Signs of the Times, 10, no 30 (7 de agosto, 1884), 465. 
diáconos tienen que ver básicamente con cualidades personales, morales y espirituales de la familia (1 Ti 3:1-9). El esposo incrédulo y los hijos son santificados por la presencia de la esposa creyente en el hogar (1 Co 7:14). Heaton y Goodman afirman:

"La influencia de la religión comienza cuando los padres usan los valores religiosos en la socialización de sus hijos. Los ritos religiosos marcan eventos importantes en el ciclo de vida, como la pubertad, el matrimonio, el nacimiento de niños y la muerte. La religión regula el comportamiento sexual premarital, la selección del compañero, el tamaño de la familia y la estabilidad matrimonial." 92

Elena G. de White hace uso de la expresión altar de la familia para referirse al culto familiar. ${ }^{93}$ En ese contexto, afirma que "el padre es el sacerdote de la familia, en cuyo altar ofrece sacrificio matutino y vespertino". ${ }^{94}$ Tam-

92 T.B Heaton y K. L. Goodman, "Religion and Family Formation", Review of Religious Research 26, n 4 (1985): 344.

93 White, Servicio cristiano, 259; White, Conducción del niño, 489; White, El ministerio de curación, 304; Elena G. de White, Joyas de los testimonios, Florida, Bs. As.: Asociación Casa Editora Sudamericana, 1975), 2:136.

94 White, El ministerio de curación, 304. bién asevera: "como los patriarcas de antaño, levantad un altar al Señor dondequiera plantéis vuestra tienda. Se necesita una reforma en este aspecto: una reforma que sea profunda y amplia". ${ }^{95}$

Kangas, estudió un grupo de 1511 adolescentes de 15 y 16 años de la División Norteamericana. Encontró que los jóvenes que reportaban mayor frecuencia en la realización del culto familiar se sentían más felices con la religión. ${ }^{96}$

Korniejczuk, en una investigación con adolescentes de 15 y 16 años de Argentina y Paraguay, descubrió que los jóvenes que participan del culto familiar y tienen una vida devocional regular, tienen actitudes positivas hacia la religión. ${ }^{97} \mathrm{~A}$ su vez, a medida que aumenta la frecuencia en la participan del culto de familia, también se incrementa la actitud positiva hacia algunas creencias fundamentales, como el sacrificio de Jesús y su segunda venida. ${ }^{98}$

En otro estudio, llevado a cabo por Dudley, se asocia la per-

95 White, Servicio cristiano, 259.

96 Kangas, 138.

97 Korniecjzuk, 207.

98 Ibíd., 156, 160. 
manencia en la iglesia por parte de los adolescentes y su participación frecuente en el culto familiar en los últimos diez años. ${ }^{99}$

\section{El baile}

Se analiza el baile a la luz de la Biblia, los escritos de Elena G. de White y lo que sostiene la Iglesia Adventista del Séptimo Día considerando la música y el ambiente.

\section{El baile en la Biblia}

En las Sagradas Escrituras, hay 28 referencias al baile o la danza, de las cuales 23 se encuentran en el Antiguo Testamento y 5 en el Nuevo Testamento. En su amplia mayoría, aluden a casos de expresión de sano gozo y alegría, muchas veces asociadas a la adoración religiosa. ${ }^{100}$ El salmista David expresa: "Has cambiado mi lamento en baile; desataste mi cilicio, y me ceñiste de alegría" (Sal 30.11). El sabio Salomón, como contraparte dice: "Cesó el gozo de nuestro corazón; nuestra danza se cambió en luto" (Lm 5:15). Haciendo uso del paralelismo

99 Dudley, "Youth Religious Commitment over Time: a Longitudinal Study of Retention", 116-118.

100 Carlos A. Steger, "El baile", Revista adventista, abril 1998, 22. hebreo, él menciona: "tiempo de llorar, y tiempo de reír; tiempo de endechar, y tiempo de bailar" (Ec 3:4). Aquí, la expresión "bailar" aparece en claro contraste con "endechar", así como ocurre con las expresiones "reír" y llorar".

Otros ejemplos de la danza como una demostración de alegría se observa en la hija de Jefté, que salió a recibir a su padre que volvía victorioso de la guerra, "con panderos y danzas" (Jue 11:34). Cuando las mujeres salieron a recibir a Saúl y David lo hicieron "con cánticos de alegría” (1 S 18:6) y danzando para festejar el triunfo sobre Goliat y los filisteos. En otra ocasión, cuando transportaba el arca de Dios a Jerusalén, David danzó con alegría y júbilo (2 S 6:14-15). Reconociendo David que Dios lo había guiado expresó: "por tanto, danzaré delante de Jehová" (2 S 6:21). En el mismo sentido, el salmista invita a adorar a Jehová diciendo: "Alaben su nombre con danza" (Sal 149:3) y "alabadle con pandero y danza" (Sal 150:4).

Los israelitas nunca bailaban en grupos mixtos. ${ }^{101}$ Danzaban

101 Steger, 23; H. M. Wolf, "Dancing", The Zondervan Pictorial Encyclopedia of the Bible, Merril C. Tenney, 
las mujeres solas, o los hombres solos, pero no juntos (Ex 15:20; Jue 11:34; 21:21,23; 1 S 18:6,7; $21: 11 ; 29: 5 ; 2 \mathrm{~S} 6: 14,16,21 ; 1 \mathrm{Cr}$ 15:29). La única excepción clara es cuando el pueblo adoró el becerro de oro. Cuando Moisés bajó al campamento "vio el becerro y las danzas" (Ex 32:19) y se llenó de ira. Este pasaje muestra el rechazo de Moisés y de Dios por esta danza, que no solo fue sensual ${ }^{102}$ sino que además desplazó el centro de adoración de Dios a un becerro de oro.

Las Escrituras no indican que hombres y mujeres bailaran románticamente juntos, como lo 22 hacen las parejas hoy. ${ }^{103}$ "Aunque la manera de danzar no se conoce en detalle, es claro que hombres y mujeres generalmente no danzaban juntos, y no hay ed. (Grand Rapids, MI: Zondervan Publishing House, 1978), 2:12; Hendrik F. Stander, "Dance", Encyclopedia of Early Christianity, Everett Ferguson, ed. (New York: Gargland Publishing Inc., 1997), 1:317.

102 Carlos Steger, 24; Nicolás Bergier, "Danza", Diccionario de teología (Madrid, Imprenta de D. Primitivo Fuentes, 1846), 2:9.

103 Wally Odum, Tom Gulbronson y David Baird, "Dance in the Old Testament", en The Complete Library of Christian Worship: The Biblical Fundations of Christian Worship, ed. Robert E. Webber (Peabody, MA: Hendrickson Publishers, 1993), 1:263. real evidencia de que alguna vez haya sucedido". ${ }^{104}$ Las danzas podían ser procesionales, circulares o estáticas. ${ }^{105}$ No se realizaban como una diversión sensual, sino como expresión de adoración a Dios y alegría. ${ }^{106} \mathrm{No}$ era pasional ni licenciosa. 107 "No existe pasaje bíblico que insinúe una connotación sexual para la danza... Tampoco hay referencias a bailes realizados de noche, sino de día y al aire libre". ${ }^{108}$

En el Nuevo Testamento, aparece el baile sensual de la hija de Herodías. Evidentemente no fue algo que Dios aprobó. Culminó con la decapitación de Juan el Bautista (Mt 14:6; Mr 6:22). No hay, en el Nuevo Testamento, referencias al baile como parte del culto de adoración a Dios. Los apóstoles no incluyeron la danza dentro de la forma de alabar a Dios al organizar la iglesia cristiana. ${ }^{109}$

En la historia del cristianis104 Wolf, 2:12.

105 Samuele Bacchiocchi, "El baile en la Biblia", Diálogo universitario $12, \mathrm{n}^{\circ}$ 3, (2000): 25.

106 "Danzas" [Ėx 15:20], Comentario bíblico adventista, ed. Francis D. Nichol, trad. Víctor Ampuero Matta (Boise: Publicaciones Interamericanas, 1990), 1:584.

107 Steger, 24.

108 Ibíd.

109 Ibíd. 
mo, en los primeros seis siglos de concilios, como el de Laodicea (año 357), el tercer concilio de Toledo (año 589), y otros, la iglesia prohibió danzar a los fieles. ${ }^{110}$

La danza a la cual hace referencia el Antiguo Testamento no puede ser comparada con el baile social moderno. Los modos de danzar expresados en la Biblia, como el gozo, la gratitud y la adoración, son diametralmente opuestos de aquellos que existen en los lugares de bailes modernos, como la sensualidad, la excitación, y la seducción. ${ }^{111}$

\section{El baile en los escritos de Elena G. de White}

Elena G. de White nunca aprobó el baile. Refiriéndose al deber de los padres en la educación de sus hijos menciona: "No se dejarán absorber por las costumbres del mundo; no se

110 Bergier, 10; Suzanne Youngerman, "Dance: Early Christianity through the Middle Ages", en The Encyclopedia of Religion, ed. Mircea Eliade (New York: Macmillan Publishing Company, 1987), 4:222.

111 Miroslav M. Kiš, "Christian Lifestyle and Behavior", en Handbook of Seventh-day Adventist Teology, ed. Raoul Dederen, vol. 12 de Seventh-day Adventist Bible Commentary, ed. George W. Reid (Hagerstown, MD: Review and Herald Publishing Association, 2000), 711. entregarán a fiestas, conciertos, bailes, a dar y a asistir a banquetes porque así lo hacen los gentiles". 112

Por otro lado, también asevera que el baile y a otras diversiones "destruyen todo aprecio por los pensamientos serios y los servicios religiosos", 113 "no implantan en el alma un solo sentimiento virtuoso o santo", 114 "ofuscan los sentidos y quitan el temor de Dios" 115 y "son un medio que Satanás usa para hacer que los hombres se olviden de Dios y le deshonren".116 También menciona que quienes frecuentan el salón de baile, "marchan como bueyes al matadero", 117 "no tienen en cuenta la eternidad...son conducidos por el gran apóstata, y con él serán destruidos". 118

112 Elena G. de White, "No se necesita sacrificar los hijos a Moloc" [Exodo 23:10], de Comentario bíblico adventista, ed. Francis D. Nichol, trad. Víctor E. Ampuero Matta (Florida, Bs. As.: Asociación Casa Editora Sudamericana, 1993), 2:1033.

113 Elena G. de White, El hogar cristiano, 469.

114 White, El hogar cristiano, 469.

115 Elena G. de White, La temperancia (Florida, Bs. As.: Asociación Casa Editora Sudamericana, 1969), 45.

116 White, El hogar cristiano, 470.

117 White, La temperancia, 204.

118 Elena G. de White, Joyas de los testimonios (Mountain View, CA: Pacific Press Publishing Association, 1953), 
La escena de Números 25, donde se registra el caso del pueblo de Israel en plena apostasía en Moab muestra la apostasía de manera clara: la música y el baile los llevó a beber vino. Esto los condujo a actos lascivos con las mujeres paganas y finalmente a la idolatría.

\section{El baile y la Iglesia Adventista del Séptimo Día}

La IASD sostiene que aunque la recreación es necesaria, la misma debe tender a "fortalecer y reparar. No fomentará el egoísmo, la rivalidad, la hostilidad, las luchas, el amor por el dominio, el amor por los placeres o una excitación malsana". ${ }^{119}$

A su vez, la iglesia adventista afirma que el baile ejerce una mala influencia ${ }^{120}$ e invita a los miembros y sus dirigentes a no patrocinar diversiones, uniéndo-

3:13-14.

119 Iglesia Adventista del Séptimo Día - Departamento de Comunicación de la DSA. Declaraciones, orientaciones $y$ otros documentos (Florida, Bs. As.: Asociación Casa Editora Sudamericana, 2000), 27.

120 Asociación General de la Iglesia Adventista del Séptimo Día. Manual de la iglesia. Edición revisada, 5ta ed. (Florida, Bs. As.: Asociación Casa Editora Sudamericana, 2006), 182. se de esta manera "a las multitudes de mundanos, negligentes y amantes del placer, amadores de los deleites más que de Dios”. ${ }^{121}$

Asimismo, en el sumario de creencias fundamentales de la Iglesia Adventista, incorporadas al Manual de la iglesia, bajo el número 25 se declara:

"En la vida cristiana hay una completa separación de las prácticas del mundo, tales como los juegos de naipes, la asistencia a los teatros y cinematógrafos, a bailes, etc., que tienden a amortecer y destruir la vida espiritual". ${ }^{122}$

Aun cuando algunos encuentran elementos positivos en el baile, especialmente desde el punto de vista de la salud, ${ }^{123}$ hay otros aspectos que deben considerarse como la música y el ambiente.

La música, en la Biblia, ocu-

121 Ibíd., 183.

122 Manual de la iglesia, 230.

123 G. Kreutz, "Does Partnered Dance Promote Health? The Case of Tango Argentino", The Journal of the Royal Society of the Promotion of Health 128, no 2 (2008): 79; Joe Verghese, "Cognitive and Mobility Profile of Older Social Dancers", Journal of the American Geriatrics Society 54, no 8 (2006): 1241; Jorge A. Costa e Silva., "Psychosocial Aspects of Dance and Music of the Brazilian Carnival", Annales Medico-psychologiques 140, no 5 (1982): 493. 
pa un lugar de importancia. El pueblo de Israel tenía músicos (1 Cr $15: 16,22,42 ; 25: 6 ; 2 \mathrm{Cr}$ $5: 13 ; 7: 6 ; 34: 12)$, cantores $(1$ Cr $6: 31-32 ; 15: 27 ; 25: 7)$ e instrumentos (1 Cr 15:16;16:5; 23:5; 2 Cr 5:13; 29:26; 30:21; Neh $12: 36)$, para que toda la congregación pudiera alabar a Dios (2 Cr $5: 13 ; 23: 13)$.

Tanto la música como el canto están generalmente asociados a la alabanza a Dios (Sal 150; Is 49:13; Lc 2:13; Hch 2:47; 16:25; Ef 5:19; Ap 5:11-13) de manera alegre y gozosa (2 Cr 23:13; 29:30; Sal 9:1-2; 66:1-2; 95:1-2; 97:12; 100:1; 122:1-4; Is 51:3; 52:9; Neh 12:43; Lc 19:37; Stg 5:13).

Elena G. de White dice que la música puede ser un instrumento de bendición o de maldición, dependiendo del uso que se haga de ella. ${ }^{124}$ Menciona que la música debería expresar reverencia por las cosas espirituales y eternas $^{125}$ y tener belleza, majestad y poder. ${ }^{126}$ También afirma

124 White, Patriarcas y profetas, 644-645.

125 Elena G. de White, Mensaje para los jóvenes, 3ra ed. (Mountain View, CA: Pacific Press Publishing Association, 1957), 429.

126 Elena G. de White, Joyas de los testimonios (Florida, Bs. As.: Asociación Casa Editora Sudamericana, 1975): que en la escuela de los profetas, la música se empleaba "con un propósito santo, para elevar los pensamientos hacia lo que es puro, noble y enaltecedor, para despertar en el alma la devoción y la gratitud hacia Dios". 127

Además dice que cantar para la gloria de Dios ahuyenta al enemigo. ${ }^{128}$ (1 S 16:23). Por otro lado, ella afirma que cuando es mal empleada, la música "llega a ser uno de los instrumentos más seductores de la tentación”. ${ }^{29}$

La música, para el adolescente, es un culto a los sentidos. En un estudio con adolescentes, el $60,3 \%$ dice "elegir habitualmente música que divierta y anime". 130 A su vez, es un "poderoso medio para la comunicación de ideas"131 e influenciar a las personas, incluso, en su conducta. ${ }^{132}$

Por otro lado, más estudios

1:458.

127 White, Patriarcas y profetas, 644-645.

128 Elena G. de White, Mensajes selectos, 3era ed. (Mountain View, CA: Pacific Press Publishing Association, 1986): 3:379.

129 White, La voz: su educación y uso correcto, 451.

130 Megías Quirós, 96.

131 Kišs, 711-712.

132 Ibíd.; Tía DeNora, Music in Everyday Life (Reino Unido: Cambridge University Press, 2000), 17. 
se refieren a las letras de las canciones, que de manera explícita hacen alusión a la violencia, el alcohol, el sexo y las drogas. ${ }^{13}$

El ambiente es otro elementos del baile, generalmente cada lugar tiene un ambiente preparado de acuerdo a las actividades que se realizan en él. Éste, ejerce una influencia sobre las personas e impacta sobre ellas de manera positiva o negativa. ${ }^{134}$ La música, el volumen, la iluminación, la decoración, la venta de bebidas alcohólicas y tabaco, son algunos elementos que forman parte del ambiente de todo lugar de baile.

Elena G. de White relaciona el salón de baile con un lugar de excitación, diversión, frivolidad, promiscuidad, bebidas alcohólicas y tabaco. ${ }^{135}$ También dice

133 Anderson y Carnagey, 969; Brian A. Primack et al., "Content Analisys of Tobacco, Alcohol, and Other Drugs in Popular Music", Archives of Pediatrics \& Adolescent Medicine 162, n² (2008): 173.

134 Timothy Gillespie, "Dancing to the Lord", en Shall We Dance: Rediscovering Christ-Centered Standards, ed. Steve Case (Riverside, CA: La Sierra University Press, 1996), 91.

135 White, That I May Know Him, 318; Elena G. de White, El Deseado de todas las gentes, 5ta ed. (Mountain View, CA: Pacific Press Publishing Association, 1971), 192; White, Mensaje para los que allí "se sacrifica la salud y la moral en aras del placer". ${ }^{136}$

Algunas investigaciones relacionan los lugares de baile, como discotecas y pubs, con el consumo de substancias como el alcohol, ${ }^{137}$ el tabaco ${ }^{138}$ y las drogas. ${ }^{139}$

Algunos principios que pueden ayudar a un adolescente a decidir si es conveniente ir a un lugar bailable, podrían ser los siguientes: El principio de la presencia de Dios, ${ }^{140}$ del ejemplo de Jesús, ${ }^{141}$ de la pureza, ${ }^{142}$ de los cami-

jóvenes, 293, 397; White, La temperancia, 45; White, El hogar cristiano, 475; White, Mente, carácter y personalidad, 2:755.

136 White, Patriarcas y profetas, 766.

137 M. Virginia Wilmerding et al., "Cigarette Smoking in the Adolescent Dance Population", Medical Problems of Performing Artists 17, no 3 (2002): 116120.

138 Ibíd.

139 Karenza Moore y Steven Miles, "Young People, Dance and the Sub-cultural Consumption of Drugs", Addiction Research \& Theory 12, n 6 (2004): 507523.

140 Kiš, 709

$141 \mathrm{Kiš}, 709$

142 Steve Case, "Ground Rules", en Shall We Dance: Rediscovering ChristCentered Standards, ed. Steve Case (Riverside, CA: La Sierra University Press, 1996), 48. 
nos opuestos y de adoración. ${ }^{143}$

\section{Metodología}

La presente investigación es de tipo empírica, cuantitativa, descriptiva - correlacional. Es de tipo empírica y cuantitativa porque las variables son observables y medibles en la realidad. Es descriptiva, porque se medirán cada una de las variables de estudio. Es correlacional, porque se establece entre las diversas variables y sus dimensiones.

El diseño de la investigación es no experimental, ya que el investigador no manipuló ninguna de las variables. También es de corte transversal, porque el instrumento de observación se aplicó una sola vez.

\section{Población y muestra}

La población vive en el territorio eclesiástico de la AAN comprende el norte de la provincia de Santa Fe y las provincias de Corrientes, Chaco, Misiones y Formosa. La población a estudiar es el total de jóvenes de 13 a 18 años de edad que al 1 de enero de 2008 eran miembros de la

143 Elena G. de White, "Rejoice in the Lord Alway", The Youth's Instructor $49, \mathrm{n}^{\circ} 2$ (10 de enero, 1901), 10.
IASD en las noventa iglesias organizadas que existían en dicha asociación. La feligresía total de todas estas iglesias era de 16.926 miembros, de los cuales, 3.221 eran jóvenes de 13 a 18 años de edad, representando el $19 \%$ del total. ${ }^{144}$

\section{Muestra}

Se estableció el tamaño de la muestra de manera probabilística y se determinó que la muestra era de 343 adolescentes. Luego, se seleccionó 42 iglesias utilizando el programa Random Integer Generator

\section{Definición de variables}

La variable Grado de apoyo familiar (GAFa) se define conceptualmente como el nivel de apoyo que recibe el adolescente de parte de los familiares con quienes vive, a través de las siguientes dimensiones: la religiosidad de los padres, el ambiente familiar, el soporte parental, el control parental y el culto familiar.

Cada uno de las cinco dimensiones de esta variable fueron ob-

144 Sistema de Secretaría de la Asociación Argentina del Norte, al 15 de enero de 2008. Información brindada por Elida Roscher, secretaria. 
servadas de la siguiente manera: la religiosidad de los padres, con los ítems 1, 2, 8, 9, 17, 18, $31 \mathrm{y}$ 32; el ambiente familiar, con los ítems 3, 5, 10, 26 y 35; el soporte parental, con los ítems 4, 7, 11, 19 y 23; el control parental, con los ítems $12,13,14,16$ y 21 y el culto familiar, con los ítems 6 , 15,20 y 22 .

\section{Grado de adhesión a la nor- ma de conducta cristiana de no bailar}

La variable Grado de adhesión a la norma de conducta cristiana de no bailar (GANB) se define conceptualmente como el nivel de aceptación o conformidad con la norma de conducta sustentada por la IASD de que un miembro de iglesia no debe participar en bailes. Se la observó instrumentalmente. El adolescente debió elegir una de las 5 opciones propuestas en cada ítem del instrumento. Operacionalmente se la midió con una escala ordinal de 11 a 55, considerando la suma de las respuestas a los 11 ítems.

\section{$\mathrm{El}$ instrumento}

El instrumento que se utilizó es una encuesta conteniendo dos escalas, preparadas por el investigador: la escala Grado de Apoyo Familiar (GAFa) y Escala Grado de Adhesión a la Norma de no Bailar (GANB). Se realizó la prueba de confiabilidad estadística del instrumento, a través del coeficiente Alfa de Cronbach. Como resultado, el instrumento en su conjunto, que incluye los 38 ítems de las dos escalas, obtuvo un valor de 0,80 . Este valor indica que el mismo tiene un nivel de confiabilidad elevado.

Además, se aplicó la misma prueba a cada escala. La escala Grado de Apoyo Familiar (GAFa) obtuvo un valor de 0,72, lo que indica un nivel aceptable de confiabilidad, con tendencia a ser elevado. La escala Grado de Adhesión a la Norma de no Bailar (GANB) obtuvo un valor de 0,78 , lo que indica que tiene un nivel aceptable de confiabilidad, muy cerca a ser elevado.

\section{Proceso de recolección de datos}

Después de definir la muestra y de reproducir la encuesta ya validada, el investigador envió una carta al pastor Carlos Gill, quien entonces era presidente de la AAN, solicitando autoriza- 
ción para hacer el estudio en el territorio eclesiástico.

La aplicación del instrumento fue hecha por el investigador y algunos pastores de las iglesias seleccionadas.

La aplicación de la encuesta se realizó en días sábados por la mañana, en alguna de las siguientes ocasiones: entre la Escuela Sabática y el Culto de Adoración o después del Culto de Adoración.

Una vez que el encuestador estuvo reunido con los jóvenes, éste entregó a cada uno de ellos una encuesta y un lápiz. Entonces, solicitó a los adolescentes que leyeran bien cada ítem de la encuesta y que respondieran de acuerdo a sus convicciones personales. Les aclaró que completar la encuesta implicaba su aceptación de que las informaciones que brindaran pudieran ser usadas con fines de investigación académica. También dijo que podían levantar sus manos si necesitaban consultar por algún ítem. Una vez que los adolescentes terminaron de completar las encuestas, el encuestador les agradeció y recogió las mismas. Luego, las remitió con prontitud al investigador.

\section{Análisis de datos}

Después de reunir todas las encuestas completasse procedió introducir los datos en el programa estadístico SPSS, versión 20.0. para su posterior análisis. De las 369 encuestas que se lograron reunir, 22 de ellas fueron descartadas por tener ítems sin responder y se aceptaron 347 encuestas. Finalmente, se procedió a realizar las pruebas de correlación entre las variables estudiadas. Para ello, se aplicaron dos coeficientes estadísticos: tau b de Kendall $(\tau b)$ y rho de Spearman (rs). Ambos se utilizan para asociar variables ordinales.

\section{Resultados}

La Tabla 1, que muestra la correlación entre la variable $e^{145}$ grado de apoyo familiar y la variable grado de adhesión a la norma cristiana de no bailar es significativa por que 0,001 es menor que $0,05<$ por lo tanto se concluye que existe relación altamente significativa, aunque baja en adolescentes de 13 a 18 años

145 Roberto Hernández Sampieri, Carlos Fernández Collado y María del Pilar Baptista Lucio, Metodología de la investigación, 5ta ed. (Santa Fe, México: Mc Graw-Hill, 2010), 332. 
Tabla1. Correlación entre el grado de apoyo familiar y el grado de adhesión a la norma cristiana de no bailar en los adolescentes de la AAN, 2008

\begin{tabular}{|c|c|c|c|c|}
\hline & & & $\begin{array}{l}\text { Grado de apoyo } \\
\text { familiar }\end{array}$ & $\begin{array}{l}\text { Grado de adhe- } \\
\text { sión a la norma } \\
\text { cristiana de no } \\
\text { bailar }\end{array}$ \\
\hline \multirow{6}{*}{$\begin{array}{c}\text { Tau b } \\
\text { de Kendall } \\
(\tau b)\end{array}$} & \multirow{3}{*}{$\begin{array}{l}\text { Grado de apoyo } \\
\text { familiar }\end{array}$} & $\begin{array}{l}\text { Correlación } \\
\text { Coeficiente }\end{array}$ & 1,000 & ,144 \\
\hline & & Sig. (bilateral) & & ,001 \\
\hline & & $\mathrm{n}$ & 347 & 347 \\
\hline & \multirow{3}{*}{$\begin{array}{l}\text { Grado de adhe- } \\
\text { sión a la norma } \\
\text { cristiana de no } \\
\text { bailar }\end{array}$} & $\begin{array}{l}\text { Correlación } \\
\text { Coeficiente }\end{array}$ & , 144 & 1,000 \\
\hline & & Sig. (bilateral) &, 001 & \\
\hline & & $\mathrm{n}$ & 347 & 347 \\
\hline \multirow{6}{*}{$\begin{array}{l}\text { Rho de } \\
\text { Spearman } \\
\text { (rs) }\end{array}$} & \multirow{3}{*}{$\begin{array}{l}\text { Grado de apoyo } \\
\text { familiar }\end{array}$} & $\begin{array}{l}\text { Correlación } \\
\text { Coeficiente }\end{array}$ & 1,000 & ,177 \\
\hline & & Sig. (bilateral) & ,001 & \\
\hline & & $\mathrm{n}$ & 347 & 347 \\
\hline & \multirow{3}{*}{$\begin{array}{l}\text { Grado de adhe- } \\
\text { sión a la norma } \\
\text { cristiana de no } \\
\text { bailar }\end{array}$} & $\begin{array}{l}\text { Correlación } \\
\text { Coeficiente }\end{array}$ & ,177 & 1,000 \\
\hline & & Sig. (bilateral) & ,001 & \\
\hline & & $\mathrm{n}$ & 347 & 347 \\
\hline
\end{tabular}

\section{Prueba de hipótesis específica uno}

La Tabla 2 muestra que la religiosidad de los padres y el grado de adhesión a la norma cristiana de no bailar es significativa debi- do a que $0,000<0,05$, indicando que existe una correlación positiva y altamente significativa, por lo tanto, se aceptaa la hipótesis alterna en los adolescentes de 13 a 18 años de edad. 
Tabla 2. Correlación entre la religiosidad de los padres y el grado de adhesión a la norma cristiana de no bailar en los adolescentes de la AAN, 2008

\begin{tabular}{|c|c|c|c|c|}
\hline & & & $\begin{array}{l}\text { Religiosidad } \\
\text { de los padres }\end{array}$ & $\begin{array}{c}\text { Grado de adhe- } \\
\text { sión a la norma } \\
\text { cristiana de no } \\
\text { bailar }\end{array}$ \\
\hline \multirow{6}{*}{$\begin{array}{c}\text { Tau b } \\
\text { de Kendall } \\
(\tau b)\end{array}$} & \multirow{3}{*}{$\begin{array}{l}\text { Religiosidad } \\
\text { de los padres }\end{array}$} & $\begin{array}{l}\text { Correlación } \\
\text { Coeficiente }\end{array}$ & 1,000 & ,268 \\
\hline & & Sig. (bilateral) & & ,000 \\
\hline & & $\mathrm{n}$ & 347 & 347 \\
\hline & \multirow{3}{*}{$\begin{array}{c}\text { Grado de adhe- } \\
\text { sión a la norma } \\
\text { cristiana de no } \\
\text { bailar }\end{array}$} & $\begin{array}{l}\text { Correlación } \\
\text { Coeficiente }\end{array}$ & ,268 & 1,000 \\
\hline & & Sig. (bilateral) &, 000 & \\
\hline & & $\mathrm{n}$ & 347 & 347 \\
\hline \multirow{6}{*}{$\begin{array}{l}\text { Rho de } \\
\text { Spearman } \\
\text { (rs) }\end{array}$} & \multirow{3}{*}{$\begin{array}{l}\text { Religiosidad } \\
\text { de los padres }\end{array}$} & $\begin{array}{l}\text { Correlación } \\
\text { Coeficiente }\end{array}$ & 1,000 & ,334 \\
\hline & & Sig. (bilateral) & ,000 & \\
\hline & & $\mathrm{n}$ & 347 & 347 \\
\hline & \multirow{3}{*}{$\begin{array}{l}\text { Grado de adhe- } \\
\text { sión a la norma } \\
\text { cristiana de no } \\
\text { bailar }\end{array}$} & $\begin{array}{l}\text { Correlación } \\
\text { Coeficiente }\end{array}$ & ,334 & 1,000 \\
\hline & & Sig. (bilateral) & ,000 & \\
\hline & & $\mathrm{n}$ & 347 & 347 \\
\hline
\end{tabular}

Prueba de hipótesis específica dos

En la Tabla 3 se puede ver que el ambiente familiar y el grado de adhesión a la norma cristiana de no bailar no tiene correlación significativa porque $0,233>0,05$. 
Tabla 3. Correlación entre el ambiente familiar y grado de adhesión a la norma cristiana de no bailar en los adolescentes de la AAN, 2008

\begin{tabular}{|c|c|c|c|c|}
\hline & & & $\begin{array}{l}\text { Ambiente } \\
\text { familiar }\end{array}$ & $\begin{array}{l}\text { Grado de adhe- } \\
\text { sión a la norma } \\
\text { cristiana de no } \\
\text { bailar }\end{array}$ \\
\hline \multirow{6}{*}{$\begin{array}{c}\text { Tau b } \\
\text { de Kendall } \\
(\tau \mathrm{b})\end{array}$} & \multirow{3}{*}{$\begin{array}{l}\text { Ambiente } \\
\text { familiar }\end{array}$} & $\begin{array}{l}\text { Correlación } \\
\text { Coeficiente }\end{array}$ & 1,000 & ,052 \\
\hline & & Sig. (bilateral) & & ,233 \\
\hline & & $\mathrm{n}$ & 347 & 347 \\
\hline & \multirow{3}{*}{$\begin{array}{l}\text { Grado de adhe- } \\
\text { sión a la norma } \\
\text { cristiana de no } \\
\text { bailar }\end{array}$} & $\begin{array}{l}\text { Correlación } \\
\text { Coeficiente }\end{array}$ & ,052 & 1,000 \\
\hline & & Sig. (bilateral) & ,233 & \\
\hline & & $\mathrm{n}$ & 347 & 347 \\
\hline \multirow{6}{*}{$\begin{array}{c}\text { Rho de } \\
\text { Spearman } \\
\text { (rs) }\end{array}$} & \multirow{3}{*}{$\begin{array}{l}\text { Ambiente } \\
\text { familiar }\end{array}$} & $\begin{array}{l}\text { Correlación } \\
\text { Coeficiente }\end{array}$ & 1,000 & ,067 \\
\hline & & Sig. (bilateral) & ,215 & \\
\hline & & $\mathrm{n}$ & 347 & 347 \\
\hline & \multirow{3}{*}{$\begin{array}{l}\text { Grado de adhe- } \\
\text { sión a la norma } \\
\text { cristiana de no } \\
\text { bailar }\end{array}$} & $\begin{array}{l}\text { Correlación } \\
\text { Coeficiente }\end{array}$ & ,067 & 1,000 \\
\hline & & Sig. (bilateral) & ,215 & \\
\hline & & $\mathrm{n}$ & 347 & 347 \\
\hline
\end{tabular}

\section{Prueba de hipótesis específica tres}

Soporte parental y el grado de adhesión a la norma cristia- na de no bailar no existe correlación significativa porque 0,122 es mayor que 0,05 ; por lo tanto, se acepta la hipótesis nula. 
Tabla 4. Correlación entre el soporte parental y grado de adhesión a la norma cristiana de no bailar en los adolescentes de la AAN, 2008

\begin{tabular}{|c|c|c|c|c|}
\hline & & & $\begin{array}{l}\text { Soporte } \\
\text { parental }\end{array}$ & $\begin{array}{c}\text { Grado de adhe- } \\
\text { sión a la norma } \\
\text { cristiana de no } \\
\text { bailar }\end{array}$ \\
\hline \multirow{6}{*}{$\begin{array}{c}\text { Tau b } \\
\text { de Kendall } \\
(\tau b)\end{array}$} & \multirow{3}{*}{$\begin{array}{l}\text { Soporte } \\
\text { parental }\end{array}$} & $\begin{array}{l}\text { Correlación } \\
\text { Coeficiente }\end{array}$ & 1,000 & ,067 \\
\hline & & Sig. (bilateral) & &, 122 \\
\hline & & $\mathrm{n}$ & 347 & 347 \\
\hline & \multirow{3}{*}{$\begin{array}{l}\text { Grado de adhe- } \\
\text { sión a la norma } \\
\text { cristiana de no } \\
\text { bailar }\end{array}$} & $\begin{array}{l}\text { Correlación } \\
\text { Coeficiente }\end{array}$ & ,067 & 1,000 \\
\hline & & Sig. (bilateral) & ,122 & \\
\hline & & $\mathrm{n}$ & 347 & 347 \\
\hline \multirow{6}{*}{$\begin{array}{l}\text { Rho de } \\
\text { Spearman } \\
\text { (rs) }\end{array}$} & \multirow{3}{*}{$\begin{array}{l}\text { Soporte } \\
\text { parental }\end{array}$} & $\begin{array}{l}\text { Correlación } \\
\text { Coeficiente }\end{array}$ & 1,000 & ,082 \\
\hline & & Sig. (bilateral) & , 126 & \\
\hline & & $\mathrm{n}$ & 347 & 347 \\
\hline & \multirow{3}{*}{$\begin{array}{l}\text { Grado de adhe- } \\
\text { sión a la norma } \\
\text { cristiana de no } \\
\text { bailar }\end{array}$} & $\begin{array}{l}\text { Correlación } \\
\text { Coeficiente }\end{array}$ & ,082 & 1,000 \\
\hline & & Sig. (bilateral) & ,126 & \\
\hline & & $\mathrm{n}$ & 347 & 347 \\
\hline
\end{tabular}

Prueba de hipótesis específica cuatro

Control parental y el grado de adhesión a la norma cristiana de no bailar muestra que el nivel de significancia es de $0,068>0,05$, indicando que no existe una correlación significativa, por lo tanto, se acepta la hipótesis nula. 
Tabla 5. Correlación entre el control parental y grado de adhesión a la norma cristiana de no bailar en los adolescentes de la AAN, 2008

\begin{tabular}{|c|c|c|c|c|}
\hline & & & $\begin{array}{l}\text { Control } \\
\text { parental }\end{array}$ & $\begin{array}{l}\text { Grado de adhe- } \\
\text { sión a la norma } \\
\text { cristiana de no } \\
\text { bailar }\end{array}$ \\
\hline \multirow{6}{*}{$\begin{array}{c}\text { Tau b } \\
\text { de Kendall } \\
(\tau b)\end{array}$} & \multirow{3}{*}{$\begin{array}{l}\text { Control } \\
\text { parental }\end{array}$} & $\begin{array}{l}\text { Correlación } \\
\text { Coeficiente }\end{array}$ & 1,000 & ,079 \\
\hline & & Sig. (bilateral) & & ,068 \\
\hline & & $\mathrm{n}$ & 347 & 347 \\
\hline & \multirow{3}{*}{$\begin{array}{l}\text { Grado de adhe- } \\
\text { sión a la norma } \\
\text { cristiana de no } \\
\text { bailar }\end{array}$} & $\begin{array}{l}\text { Correlación } \\
\text { Coeficiente }\end{array}$ & ,079 & 1,000 \\
\hline & & Sig. (bilateral) & ,068 & \\
\hline & & $\mathrm{n}$ & 347 & 347 \\
\hline \multirow{6}{*}{$\begin{array}{c}\text { Rho de } \\
\text { Spearman } \\
\text { (rs) }\end{array}$} & \multirow{3}{*}{$\begin{array}{l}\text { Control } \\
\text { parental }\end{array}$} & $\begin{array}{l}\text { Correlación } \\
\text { Coeficiente }\end{array}$ & 1,000 & ,097 \\
\hline & & Sig. (bilateral) & ,071 & \\
\hline & & $\mathrm{n}$ & 347 & 347 \\
\hline & \multirow{3}{*}{$\begin{array}{l}\text { Grado de adhe- } \\
\text { sión a la norma } \\
\text { cristiana de no } \\
\text { bailar }\end{array}$} & $\begin{array}{l}\text { Correlación } \\
\text { Coeficiente }\end{array}$ & ,097 & 1,000 \\
\hline & & Sig. (bilateral) & ,071 & \\
\hline & & $\mathrm{n}$ & 347 & 347 \\
\hline
\end{tabular}

\section{Prueba de hipótesis específica cinco}

En relación a culto familiar y el grado de adhesión a la norma cristiana de no bailar el nivel de significancia es de $0,008<$ 0,05 , indicando que existe una correlación positiva y altamente significativa, por lo tanto, se acepta la hipótesis alterna. 
Tabla 6. Correlación entre el culto familiar y grado de adhesión a la norma cristiana de no bailar en los adolescentes de la AAN, 2008

\begin{tabular}{|c|c|c|c|c|}
\hline & & & $\begin{array}{l}\text { Culto } \\
\text { familiar }\end{array}$ & $\begin{array}{c}\text { Grado de adhe- } \\
\text { sión a la norma } \\
\text { cristiana de no } \\
\text { bailar }\end{array}$ \\
\hline \multirow{6}{*}{$\begin{array}{c}\text { Tau b } \\
\text { de Kendall } \\
(\tau b)\end{array}$} & \multirow{3}{*}{$\begin{array}{l}\text { Culto } \\
\text { familiar }\end{array}$} & $\begin{array}{l}\text { Correlación } \\
\text { Coeficiente }\end{array}$ & 1,000 & ,115 \\
\hline & & Sig. (bilateral) & & ,008 \\
\hline & & $\mathrm{n}$ & 347 & 347 \\
\hline & \multirow{3}{*}{$\begin{array}{c}\text { Grado de adhe- } \\
\text { sión a la norma } \\
\text { cristiana de no } \\
\text { bailar }\end{array}$} & $\begin{array}{l}\text { Correlación } \\
\text { Coeficiente }\end{array}$ & ,115 & 1,000 \\
\hline & & Sig. (bilateral) & ,008 & \\
\hline & & $\mathrm{n}$ & 347 & 347 \\
\hline \multirow{6}{*}{$\begin{array}{l}\text { Rho de } \\
\text { Spearman } \\
\text { (rs) }\end{array}$} & \multirow{3}{*}{$\begin{array}{l}\text { Culto } \\
\text { familiar }\end{array}$} & $\begin{array}{l}\text { Correlación } \\
\text { Coeficiente }\end{array}$ & 1,000 & ,142 \\
\hline & & Sig. (bilateral) & ,008 & \\
\hline & & $\mathrm{n}$ & 347 & 347 \\
\hline & \multirow{3}{*}{$\begin{array}{c}\text { Grado de adhe- } \\
\text { sión a la norma } \\
\text { cristiana de no } \\
\text { bailar }\end{array}$} & $\begin{array}{l}\text { Correlación } \\
\text { Coeficiente }\end{array}$ & ,142 & 1,000 \\
\hline & & Sig. (bilateral) & ,008 & \\
\hline & & $\mathrm{n}$ & 347 & 347 \\
\hline
\end{tabular}

\section{Discusión}

Apoyo familiar y norma cristiana de no bailar

La relación significativa en- contrada entre el grado de apoyo familiar y la norma cristiana de no bailar, va en la dirección de otros estudios que de manera indirecta abordaron estas variables. 
Tanto el Valuegenesis 1, como el Valuegenesis 2, y el AVANCE, estudios abarcantes realizadosen la IASD, analizan la contribución en el desarrollo de la madurez de la fe de los adolescentes y jóvenes, toma en cuenta entre las normas culturales la variable de no bailar. ${ }^{146}$

Por un lado, estos estudios concluyen que la familia es la vía de apoyo más positiva en los adolescentes y jóvenes, para la adhesión y práctica de las normas cristianas ${ }^{147}$ y afirmam que la norma cristiana de no bailar es una de las menos aceptadas entre los adolescentes. ${ }^{148}$ En los estudios dirigidos por Dudley y Kangas, la adhesión y no adhesión de esta norma arrojó resultados similares. ${ }^{149}$

Aun cuando en el presente estudio, el porcentaje de adhesión a la norma cristiana de no bailar sea superior al de la mayoría de las otras investigaciones, la mayor parte de los adolescentes (61\%) considera que no se ad-

146 Gillespie y Donahue, 225-227.

147 Rice y Gillespie, 65-66.

148 Dudley, Valuegenesis: Faith in the Balance, 148; Gillespie y Donahue, 225; Ramírez-Johnson y Hernández, 88.

149 Dudley, Why Our Teenagers Leave the Church: Personal Stories From a 10-Year Study, 40; Kangas, 107. hiere a la norma o está indefinido. Por lo tanto, puede ser que en la presente investigación, la relación altamente significativa, pero a la vez baja, entre el grado de apoyo familiar y el grado de adhesión a la norma cristiana de no bailar, se deba a que ésta última es una de las normas menos aceptadas por los adolescentes en este tiempo.

\section{Religiosidad de los padres}

La relación altamente significativa, aunque baja, de la religiosidad de los padres con el grado de adhesión a la norma cristiana de no bailar, está de acuerdo con otros estudios. Valuegenesis 2,150 AVANCE. ${ }^{151}$ Kangas afirma que los adolescentes que perciben a sus padres viviendo de acuerdo a sus creencias religiosas, manifiestan una actitud más positiva hacia las normas de la iglesia. ${ }^{152}$

En el presente estudio, en relación a la práctica de las enseñanzas de la IASD, el 62\% afirma que el papá y el $80,7 \%$ considera que la mamá siempre o casi siempre lo hace.

150 Gillespie y Donahue, 249.

151 Ramírez-Johnson y Hernández, 80. 152 Kangas, 143. 


\section{Ambiente familiar}

La falta de correlación entre el ambiente familiar y el grado de adhesión a la norma cristiana de no bailar contradice lo que indica el Valuegenesis 1 pero para los estudios de Gillespie y Donahue, AVANCE ${ }^{153}$ y Valuegenesis 2 , afirman que hay mayor adhesión a las normas de cultura popular cuando la familia está involucrada y hay un ambiente familiar de amor. ${ }^{154}$

En la presente investigación, la falta de relación entre el ambiente familiar y el grado de adhesión a la norma cristiana de no bailar, es una de las normas menos aceptadas por los adolescentes en este tiempo.

\section{Soporte parental}

En la presente investigación, el soporte parental no tiene correlación con el grado de adhesión a la norma cristiana de no bailar. Otros estudios parecen indicar lo contrario.

\section{El estudio Valuegenesis, ${ }^{155}$}

153 Ramírez-Johnson y Hernández, $45,75$.

154 Gillespie y Donahue, 233.

155 Manners, 8.
Valuegenesis 2,156 AVANCE ${ }^{157}$ muestran que existe una relación positiva entre la comunicación o soporte parental y la adhesión a las normas.

\section{Control parental}

La falta de correlación entre el control parental y el grado de adhesión a la norma cristiana de no bailar también contradice lo que otros estudios parecen indicar.

Un estilo parental autoritativo o democrático promueve la internalización de valores en los hijos. ${ }^{158}$ Por otro lado, un estilo parental autoritario se relaciona con adolescentes alienados de la religión. ${ }^{159}$

Cuando se pretende aplicar la autoridad religiosa de un modo más duro y autocrático, especialmente cuando esta autoridad está combinada con ri-

156 Gillespie y Donahue, 255-272.

157 Ramírez-Johnson y Hernández, 95.

158 Nancy Darling y Laucence Steinberg, "Parenting Styles as Context: an Integrative Model", Psychological Bulletin 113, $n^{\circ} 3$ (1993), 492.

159 Roger Luis Dudley, "Alienation from Religion in Adolescent from Fundamentalist Religious Homes", Journal for the Scientific Study of Religion 17, $\mathrm{n}^{\circ} 4$ (1978): 396-397. 
gidez e impaciencia, los adolescentes tienden a rechazar más la religión”. ${ }^{160}$

Puede ser que en la presente investigación, la falta de relación entre el control parental y el grado de adhesión a la norma cristiana de no bailar, se deba a que es una de las normas menos aceptadas por los adolescentes.

\section{Culto familiar}

En este estudio, el culto familiar y el grado de adhesión a la norma cristiana de no bailar, fueron correlacionados de manera positiva y altamente significativa, aunque baja. Este resultado va en la misma dirección que otras investigaciones previas como la de Dudley ${ }^{161}$ Valuegenesis 1, Rice, Lee y Gillespie. $^{162}$

160 Dudley, "Alienation from Religion in Adolescent from Fundamentalist Religious Homes", 390.

161 Dudley, "Youth Religious Commitment over Time: a Longitudinal Study of Retention", 115-116.

162 162. Jerry W. Lee, Gail T. Rice y V. Bailey Gillespie, "Family Worship Patterns and their Correlation with Adolescent Behavior and Beliefs, Journal for the Scientific Study of Religion 36, no 3 (1997): 378.

\section{Conclusiones}

La investigación muestra que existe relación positiva y altamente significativa, aunque baja, entre el grado de apoyo familiar recibido y el grado de adhesión a la norma de conducta cristiana de no bailar sustentada por la IASD en los adolescentes de la Asociación Argentina del Norte.

En segundo lugar, se estableció que el grado de apoyo familiar, percibido por la mayoría de los adolescentes es muy bajo a medio para el resto, es considerado como alto y muy alto.

En tercer lugar, el grado de adhesión a la norma de conducta cristiana de no bailar, es percibido por la mayoría de los adolescentes va de muy bajo a medio, en tanto que para el resto es considerado como alto o muy alto.

En cuarto lugar, se observa que existe relación positiva y significativa, aunque baja, entre la religiosidad de los padres y el grado de adhesión a la norma de conducta cristiana.

En quinto lugar, se encuentra que no existe relación entre el 
ambiente familiar y el grado de adhesión a la norma de conducta cristiana de no bailar.

En sexto lugar, se aprecia que no existe relación entre el soporte parental y el grado de adhesión a la norma de conducta cristiana de no bailar.

En séptimo lugar, se advierte que no existe relación entre el control parental y el grado de adhesión a la norma de conducta cristiana de no bailar.

Por último, se establece que existe relación positiva y significativa, aunque baja, entre el culto familiar y el grado de adhesión a la norma de conducta cristiana de no bailar sustentada por la IASD, en los adolescentes de la AAN. 